Superalloys 2012: 12 ${ }^{\text {th }}$ International Symposium on Superalloys

\title{
Sputtered Ni-base Superalloys for Microscale Devices
}

\author{
Devin E. Burns ${ }^{1}$, Yong Zhang ${ }^{1}$, Timothy P. Weihs ${ }^{1,2}$, Kevin J. Hemker ${ }^{1,2}$ \\ ${ }^{1}$ Department of Mechanical Engineering, Johns Hopkins University, Baltimore, MD \\ ${ }^{2}$ Department of Material Science, Johns Hopkins University, Baltimore, MD
}

Keywords: Sputtering, Thin films, Mechanical properties, Precipitation kinetics, MEMS

\begin{abstract}
Metallic thin films, micro-devices and microelectromechanical systems (MEMS) suffer from a lack of thermal stability and poor mechanical properties at high temperatures. By contrast, cast and forged Ni-base superalloys have excellent high temperature properties, but shaping and processing routes for superalloy micro devices have not been developed. Here free-standing nanocrystalline foils of the Ni-based superalloy, Haynes 718, were produced by magnetron sputtering and mechanical removal from Si substrates. Precipitation studies revealed unique transformation paths compared to the bulk alloy. Heat treated foils possess yield stresses of $400 \mathrm{MPa}$ at $700^{\circ} \mathrm{C}$. These results suggest that sputtered superalloys could extend the operating ranges of micro-devices. Furthermore, nanocrystalline alloys obtained through vapor phase processing provide thermal processing paths unattainable from the melt.
\end{abstract}

\section{Introduction}

Most microelectromechanical systems (MEMS) are made of silicon. Electrodeposited metallic thin films offer a greater suite of mechanical performance at room temperature compared to silicon, but to date micro-scale processing has been limited to nearly pure metals that exhibit little thermal stability and poor mechanical properties at elevated temperatures. The dramatic difference between room temperature and elevated temperature properties is due in large part to the reliance of metallic thin films on grain boundary strengthening. In contrast, the operating temperatures of land and aero-based turbines have been dramatically improved over the past half-century, due in large part to the development of precipitation strengthened Ni-base superalloys. However, little work has been done to translate these successes into the development of more effective materials for micro-devices.

In the current study, we have developed vapor phase processing routes to produce thick superalloy foils as a means to increase the thermal stability and operating temperatures of metallic microdevices. We elected to use vapor phase processing to produce these foils because of the compatibility of these vapor phase processes with conventional silicon-based lithographic and surface micro-machining techniques. Compatibility with these techniques ensures the ability to batch produce these components in a highly parallel and efficient manner that is needed for economic feasibility. X-ray diffraction (XRD) and transmission electron microscopy (TEM) were used to study the unique microstructures and kinetic pathways that resulted from vapor deposition and subsequent heat treatments. Mechanical tests were performed at elevated temperatures and were used to verify significant improvements in the thermal stability and mechanical behavior as compared to existing metallic micro-materials.

\section{Sputtering}

Experimental Procedure

Commercially available alloy 718 plate $(6.35 \mathrm{~mm}$ thick, Haynes International) delivered in the solution heat treated condition (solutionized at $1000^{\circ} \mathrm{C}$ and then quenched in water) was water jet cut into $10 \mathrm{~cm}$ diameter sputter targets. The 718 was magnetron sputtered onto $400-450 \mu \mathrm{m}$ thick (100) silicon substrates. A design of experiment was conducted to minimize residual stresses in the sputtered films so that thick sputtered foils could be produced without peeling. These studies included systematically varying the target to substrate distance, sputtering gas pressure, and sputtering rate as displayed in Table 1 . Residuals stresses in the as-deposited films were measured using a commercial wafer curvature system from k-Space Associates. Deposition runs were carried out using argon in a high vacuum chamber with base pressures not exceeding $2.7 \times 10^{-4} \mathrm{~Pa}$. Sufficiently thick foils were produced to allow release of the superalloy film from the silicon substrate by breaking the wafer along a low index cleavage plane. Any residual silicon attached to the superalloy foil after release was removed by mechanical polishing with standard 1200 grit silicon carbide polishing papers and a $\mathrm{XeF}_{2}$ dry gas etch.

Table 1. Test parameters used in the design of experiment

\begin{tabular}{|l|l|l|l|}
\hline Run & $\begin{array}{l}\text { Ar Pressure } \\
(\mathrm{Pa})\end{array}$ & $\begin{array}{l}\text { T to S } \\
\text { distance }(\mathrm{cm})\end{array}$ & Rate $(\mathrm{W})$ \\
\hline 1 & 1.3 & 5 & 150 \\
2 & 1.3 & 10 & 450 \\
3 & 1.3 & 5 & 450 \\
4 & 0.8 & 5 & 150 \\
5 & 0.8 & 10 & 150 \\
6 & 0.8 & 5 & 450 \\
7 & 0.8 & 10 & 450 \\
8 & 1.3 & 10 & 150 \\
\hline
\end{tabular}

\section{Microstructural Characterization}

As-deposited foils were investigated using a Phillips X'Pert Pro Xray diffractometer and a Philips 420 TEM. TEM samples were prepared using a Struers twin jet electrode electropolisher containing 15 vol\% perchloric acid and 85\% ethanol. Precipitation studies were conducted in a Netzsch DSC 404C differential scanning calorimeter (DSC) system under flowing argon. Constant heating and cooling rate experiments were conducted $\left(20^{\circ} \mathrm{C} / \mathrm{min}\right)$ for temperatures ranging between $700^{\circ} \mathrm{C}$ and $1000^{\circ} \mathrm{C}$. Heat treated samples were analyzed using XRD and TEM to confirm the presence of phases and to examine the microstructure. Direct comparison of sputtered 718 foils with bulk 718 (both from the same batch of $6.35 \mathrm{~mm}$ plate) was made by subjecting both solutionized materials to a standard 718 heat treatment $\left(720^{\circ} \mathrm{C}, 8\right.$ hours; $620^{\circ} \mathrm{C}, 8$ hours). The plate was in its' as received solutionized state while the foil was sputter deposited as a solid 
solution. The heat treatment was performed in a Thermal Technology LLC vacuum furnace maintained at a base pressure of 18Pa. The furnace jacket was water cooled. Both the foil and plate were cooled as quickly as possible in the water cooled furnace during cooling sequences. Foil sections of 718 were placed in an alumina crucible and compressed during heat treatment to accommodate stress relaxation and to flatten the foils.

\section{Mechanical Characterization}

Heat treated 718 foils were tested by sectioning samples into rectangular strips $(1.3 \mathrm{~mm}$ wide, $1 \mathrm{~cm}$ long, $15 \mu \mathrm{m}$ thick) using a high speed Fortran cutting tool equipped with a diamond blade. Foils were tested in the custom designed microtensile system [1] depicted in Figure 1. The foils were first aligned in the loading fixtures and then clamped into place. Load was applied using a US Eurotek servo actuator drive and measured using a $100 \mathrm{~N}$ Entran load cell. Strain was measured optically via digital image correlation. Engineering strain was determined by averaging over the entire gauge length. The samples were heated resistively and temperature was measured using a two-color Chino IR-FA series optical pyrometer.

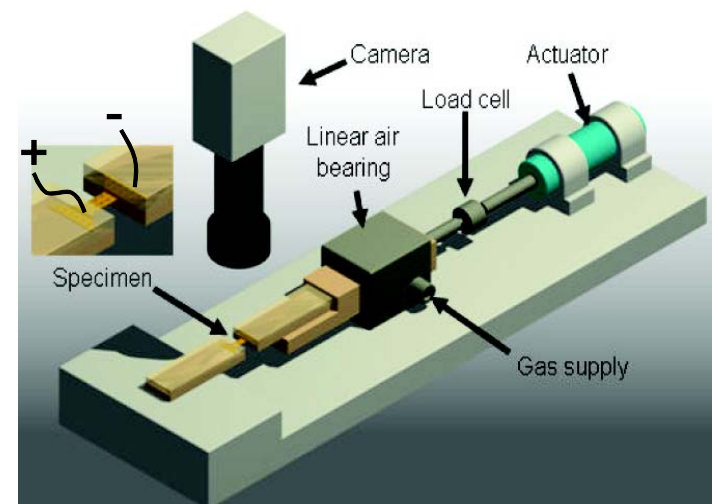

Figure 1. Depiction of the microtensile system used in this study.

\section{Sputtering}

\section{Results and Discussion}

The design of experiment revealed that sputtering rate and target to substrate distance had little effect on the residual stresses within the sputtered films. However, decreasing the argon pressure did significantly reduce stresses in the sputtered films as shown in Figure 2. Sufficiently lowering the argon pressure to $0.17 \mathrm{~Pa}$ while sputtering at $150 \mathrm{~W}$ with a target to substrate distance of $10 \mathrm{~cm}$, lowered the average in-plane biaxial stress of a $2 \mu \mathrm{m}$ thick film to approximately $125 \mathrm{MPa}$. Using these same parameters, foils up to $20 \mu \mathrm{m}$ thick were deposited on silicon.

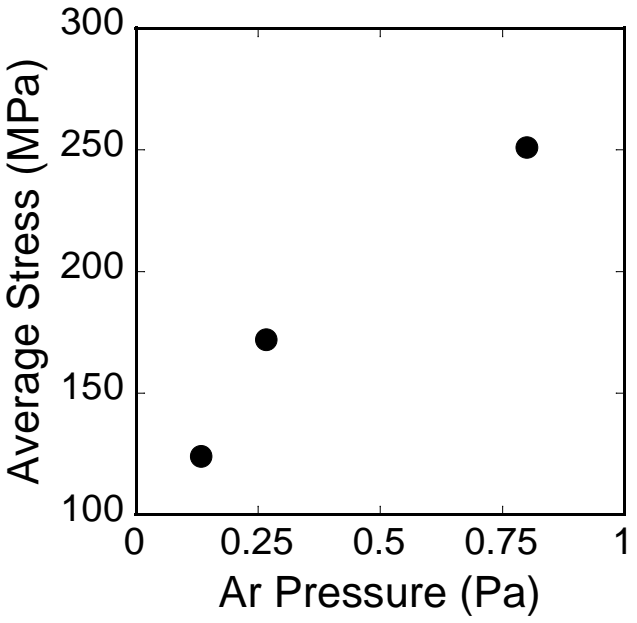

Figure 2. Plot of average in-plane biaxial stress in 718 foils on $\mathrm{Si}$ substrates as a function of Ar pressure.

\section{$\underline{\text { As-deposited } 718 \text { Foils }}$}

The XRD pattern in Figure 3(a) reveals that the 718 foils were deposited as a face centered cubic (fcc) solid solution with a predominant (111) texture. The non-equilibrium super-saturated solid solution is attributed to the very rapid cooling associated with vapor deposition. Figure 3(b) displays a TEM micrograph of the as-deposited microstructure revealing a roughly uniform $100 \mathrm{~nm}$ average grain size and no evidence of precipitates. The composition of the foil is very similar to the bulk alloy as displayed in Table 2. Here the nominal composition of alloy 718 [2] is compared to the foil's composition (rounded to the nearest percent) measured using energy dispersive spectroscopy (EDS) without standards. Some of the lighter elements (B, C) and some of the elements in lower concentration $(\mathrm{Mn}, \mathrm{Si}, \mathrm{Cu})$ were not resolvable with EDS. Room temperature microtensile tests revealed that the as-deposited foils were quite strong with fracture strengths in excess of $900 \mathrm{MPa}$, which is close to the yield strength observed in bulk 718 of 1175MPa [2]. However, with no observable plastic deformation in the foils, heat treatments were necessary to provide a balance of mechanical properties. 

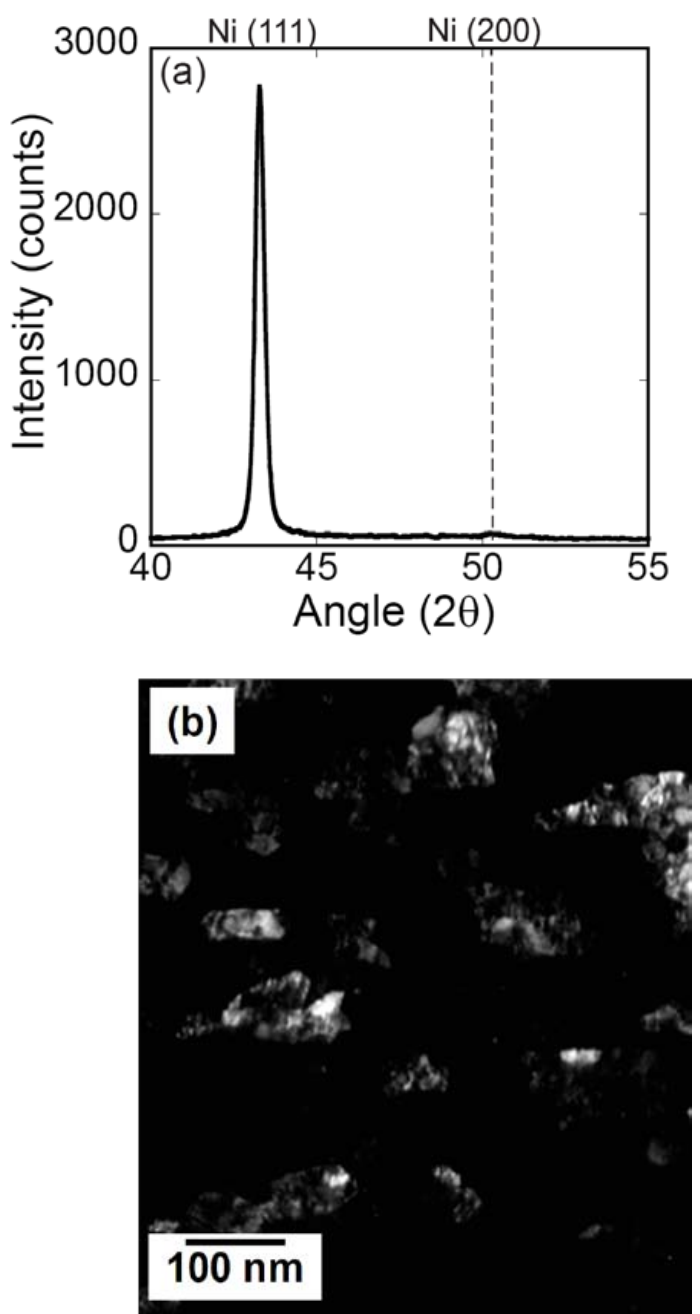

Figure 3. As deposited 718 (a) XRD pattern showing a heavily textured Ni(111) solid solution (b) Dark field TEM micrograph depicting nanocrystalline grains.

Table 2. Nominal elemental compositions for alloy 718 compared to the measured values in the sputtered foil measured using EDS.

\begin{tabular}{|l|l|l|l|l|l|l|l|l|}
\hline Alloy Wt.\% & $\mathrm{Ni}$ & $\mathrm{Co}$ & $\mathrm{Fe}$ & $\mathrm{Cr}$ & $\mathrm{Nb}+\mathrm{Ta}$ & $\mathrm{Mo}$ & $\mathrm{Ti}$ & $\mathrm{Al}$ \\
\hline Nominal [2] & 52 & 1 & 19 & 18 & 5 & 3 & 0.9 & 0.5 \\
\hline Foil & 51 & 3 & 18 & 18 & 6 & 3 & 1 & 1 \\
\hline
\end{tabular}

\section{DSC Studies}

The DSC measurements were not sensitive enough to observe the precipitation of phases out of solution. However, post analysis of the samples that had gone through DSC heat treatment gave insight into the precipitation mechanisms. Figure 4 shows the XRD patterns of 718 foils subjected to heat treatments ranging between $700^{\circ} \mathrm{C}$ and $1000^{\circ} \mathrm{C}$. Comparison of these patterns with the as-deposited pattern shown in Figure 3(a) reveals no observable changes until $900^{\circ} \mathrm{C}$. This observation is in agreement with the microstructural observations. See for example the TEM micrograph shown in Figure 5(a) of a 718 foil heated to $800^{\circ} \mathrm{C}$.
Here the microstructure is the same as that observed in the asdeposited foils; no grain growth or precipitates are seen.

At $900^{\circ} \mathrm{C}$ though, clear changes were observed in the XRD pattern. The intensity of the Ni (200) peak begins to increase in relation to the (111) peak. Furthermore, a diffraction peak corresponding to the precipitation of a secondary phase is observed just below the Ni (111) peak. This additional peak corresponds to the orthorhombic $\mathrm{Ni}_{3} \mathrm{Nb}$ phase $(\delta$ ). The $\mathrm{Ni}(222)$ peak was also observed to split into a distinct double peak signaling the precipitation of $\gamma^{\prime}-\mathrm{Ni}_{3} \mathrm{Al}$ precipitates. These XRD results agree with the TEM observations shown in Figure 5(b). The microstructure is seen to coarsen in a bimodal fashion with some grains exceeding $500 \mathrm{~nm}$ and others remaining at $100 \mathrm{~nm}$. In the larger 500nm grains, fine $\gamma^{\prime}$ precipitates appear within the grains, forming networks which resemble the original grain structure. Roughly 500nm long needle like $\delta$-phase precipitates appear in the larger grains as well.

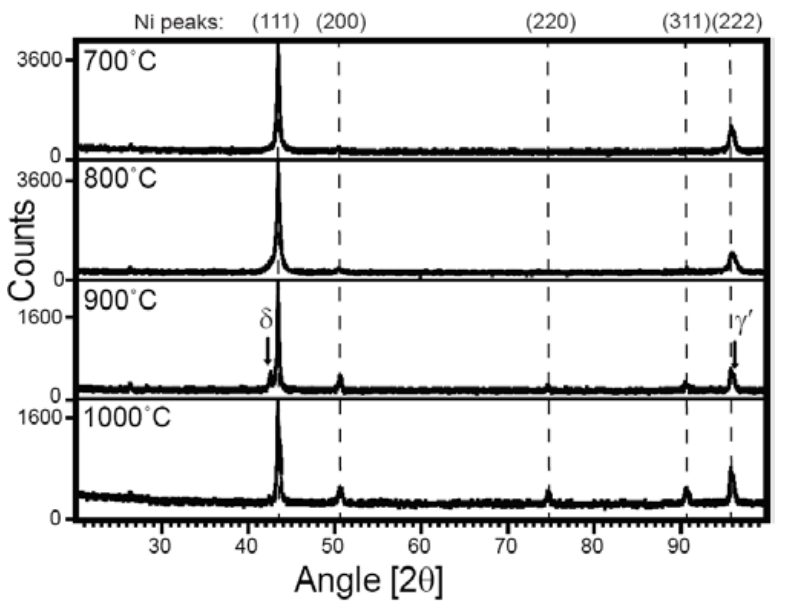

Figure 4. XRD pattern of 718 foils heat treated to temperatures ranging between $700^{\circ} \mathrm{C}$ and $1000^{\circ} \mathrm{C}$ at a heating and cooling rate of $20^{\circ} \mathrm{C} / \mathrm{min}$.

The observation of $\delta$ precipitates was unexpected, given the absence of metastable-body centered tetragonal precipitates $\left(\gamma^{\prime \prime}\right)$. Although metastable, the $\gamma^{\prime \prime}$ precipitates typically form prior to the precipitation of the thermodynamically stable $\delta$ precipitates because the lattice mismatch between the $\gamma^{\prime \prime}$ phase and the $\mathrm{Ni}$ matrix is less than that between the $\delta$ phase and the Ni matrix [3]. In the bulk, it is only after the $\gamma^{\prime \prime}$ forms and starts to coarsen at temperatures above $750^{\circ} \mathrm{C}$ (potentially above $650^{\circ} \mathrm{C}$ at longer times) that the $\delta$ phase nucleates and grows at the expense of the $\gamma^{\prime \prime}$ phase $[4,5,6]$. The nanocrystalline grain size may be responsible for the unique precipitation paths uncovered in the foils. Increased diffusion rates and a reduced nucleation barrier at the grain boundaries may account for the direct nucleation of the $\delta$ phase. Burke et. al. [7] reported the precipitation of $\delta$ in bulk samples annealed at $870^{\circ} \mathrm{C}$, and they hypothesized that the $\delta$ phase precipitated at grain boundaries and other interfaces before primary $\gamma^{\prime \prime}$. This supports the idea that the high density of grain boundaries in the nanocrystalline foils may explain the preference for $\delta$ phase precipitation. 
The XRD pattern for the foils heated to $1000^{\circ} \mathrm{C}$ indicates the dissolution of the orthorhombic $\delta-\mathrm{Ni}_{3} \mathrm{Nb}$ phase. This result is consistent with reports of the $\delta$ solvus temperature being approximately $1000^{\circ} \mathrm{C}[8,9]$. The $\mathrm{Ni}(222)$ double peak was even more pronounced after heat treating at $1000^{\circ} \mathrm{C}$ pointing to an increased volume fraction of $\gamma^{\prime}-\mathrm{Ni}_{3} \mathrm{Al}$ precipitates. This observation is supported by the TEM image shown in Figure 5(c). Here $\gamma^{\prime}$ precipitates, several nanometers in size, appear within the grains. These $\gamma^{\prime}$-precipitates do not appear to be associated with previous grain boundary positions. Additional grain growth was also observed after the $1000^{\circ} \mathrm{C}$ heat treatment.
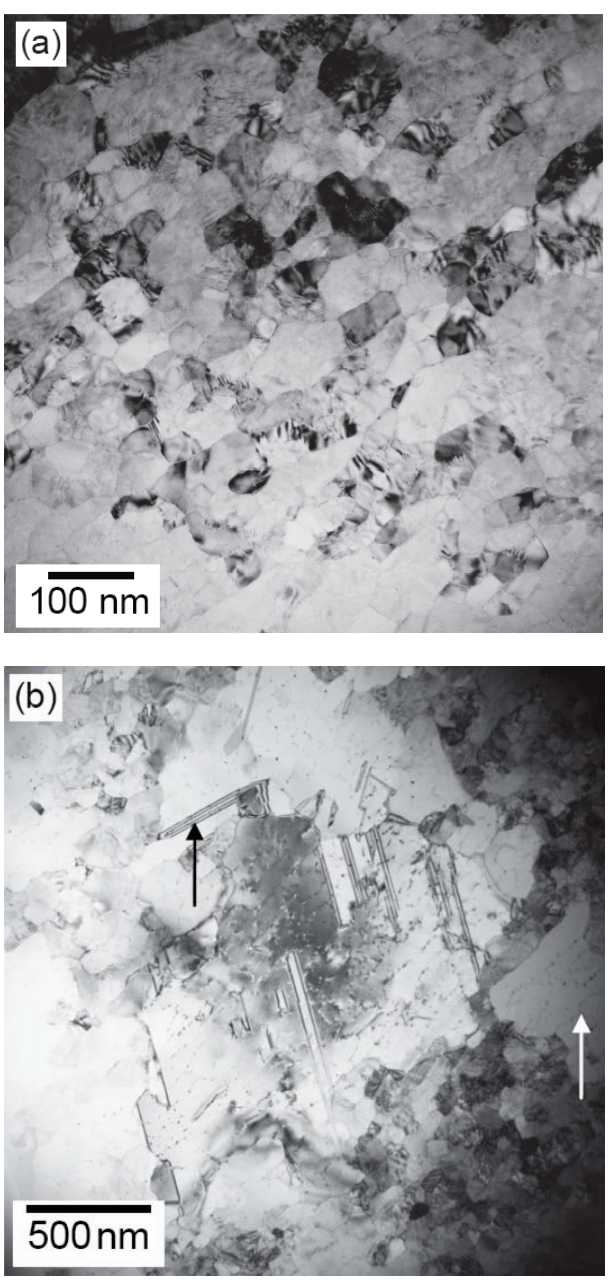

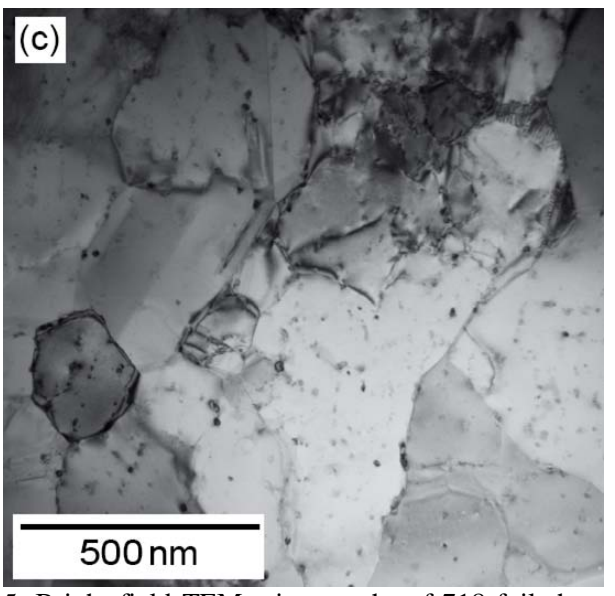

Figure 5. Bright field TEM micrographs of 718 foils heated and cooled at $\left(20^{\circ} \mathrm{C} / \mathrm{min}\right)$ to: (a) $800^{\circ} \mathrm{C} \mathrm{(b)} 900^{\circ} \mathrm{C}$ (white arrow) large grain containing small $\mathrm{Ni}_{3} \mathrm{Al}$ precipitates forming a precipitate network; (black arrow) orthorhombic $\mathrm{Ni}_{3} \mathrm{Nb}$ precipitate (c) $1000^{\circ} \mathrm{C}$.

\section{$\underline{\text { Standard } 718 \text { Heat Treatment }}$}

When both foil and bulk samples were given a standard alloy 718 heat treatment $\left(720^{\circ} \mathrm{C}, 8\right.$ hours; $620^{\circ} \mathrm{C}, 8$ hours $)$, a direct comparison of as-sputtered and heat treated 718 foils to solutionized and heat treated bulk 718 revealed distinct differences. As displayed in the TEM micrograph in Figure 6(a) and the XRD pattern show in Figure 6 (b), the $\delta$ phase was present in sputtered 718 foils. The $\delta$ phase was not present in bulk 718 foils as evidenced by the bright and dark field images shown in Figure 6 (c) and (d). Instead, large numbers of $\gamma$ '” precipitates, which are commonly observed in bulk alloys, were found. No observations were made of the $\gamma$ " precipitates in the sputtered foil. These observations are consistent with reports that $\delta$ precipitates in bulk alloys are often surrounded by $\gamma$ ' free zones $[3,6]$. It is worth noting that the sputtered foils remained ultrafined grained with some grains in excess of $500 \mathrm{~nm}$ but many others remaining around $100 \mathrm{~nm}$.

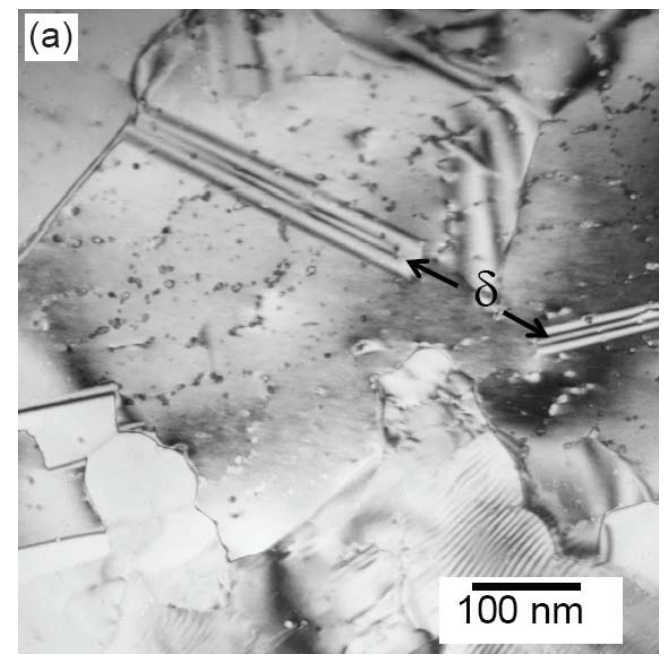



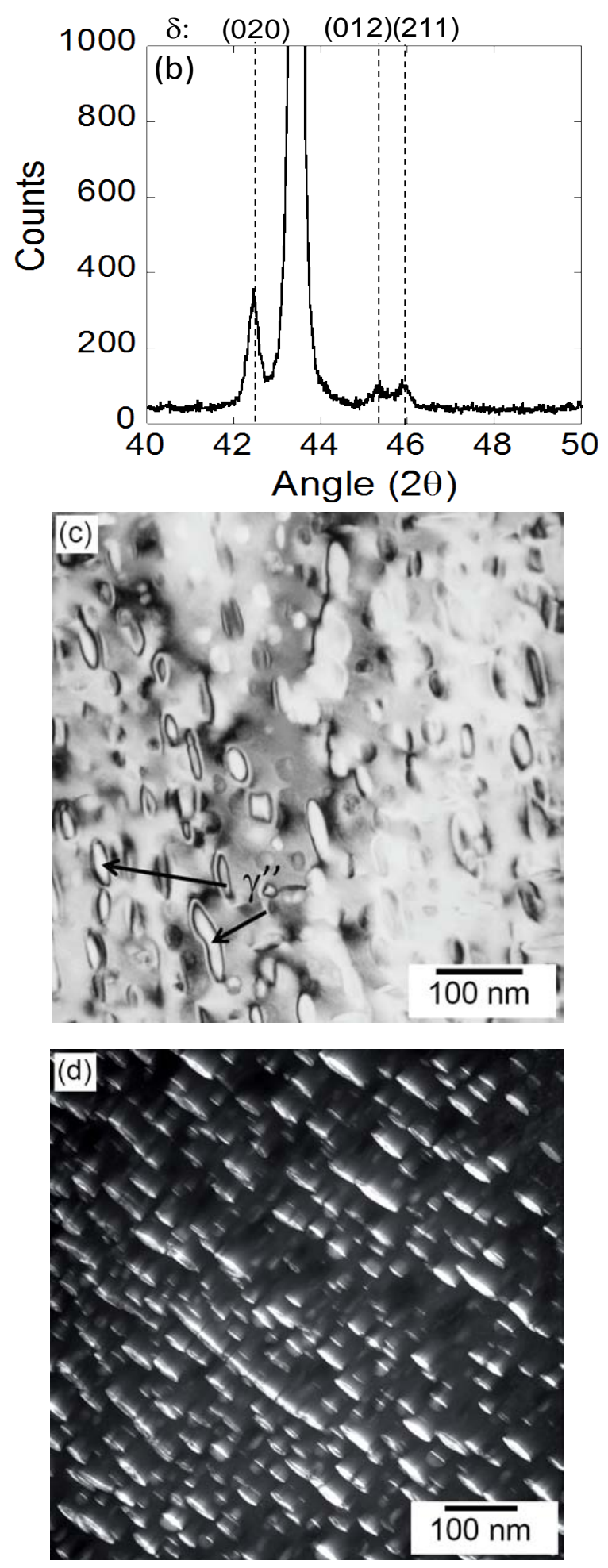

Figure 6. Alloy 718 subjected to a standard 718 heat treatment (a) bright field micrograph of foil containing orthorhombic $\mathrm{Ni}_{3} \mathrm{Nb}(\delta)$ precipitates (b) XRD pattern of foil revealing $\delta$ precipitates (c) bright field and (d) dark field micrograph of bulk alloy with tetragonal $\mathrm{Ni}_{3} \mathrm{Nb}\left(\gamma^{\prime \prime}\right)$ precipitates.

To judge the suitability of these 718 foils for high temperature applications, elevated microtensile tests were conducted at $700^{\circ} \mathrm{C}$. A representative stress-strain curve for a 718 foil is shown in Figure 7. It is evident from these data that foils can show yield stresses of around $400 \mathrm{MPa}$ with several percent ductility. Compared to conventional metallic films, these foils exhibit excellent high temperature properties. However, bulk 718 exhibits yield stresses of 750-1000 $\mathrm{MPa}$ at these temperatures with elongations of $10-20 \%$ [2]. This large discrepancy between the foil and bulk properties may be attributed to the $\delta$ phase which is indicative of over aging in the bulk material.

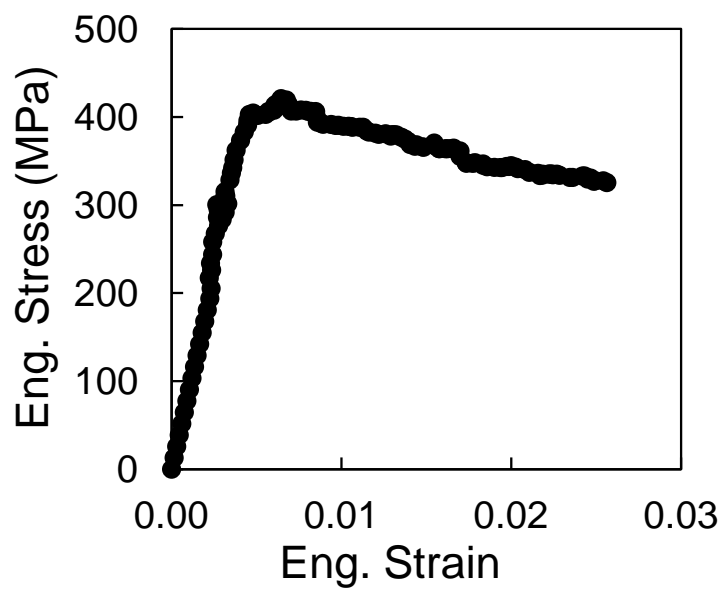

Figure 7. Representative stress-strain curve of a 718 foil tested at $700^{\circ} \mathrm{C}$ after a standard 718 heat treatment.

\section{High Temperature Treatment}

In an attempt to obtain bulk properties in the 718 foils, an initial high temperature heat treatment at $1020^{\circ} \mathrm{C}$ was performed for 30 minutes to dissolve the $\delta$ phase and grow the grains prior to performing a standard 718 heat treatment. Cooling to each of these steps was done as quickly as possible within the water cooled furnace (taking approximately 4.5 minutes to cool from $1020^{\circ} \mathrm{C}$ to $720^{\circ} \mathrm{C}$ ). The bright field TEM image shown in Figure 8(a) depicts the results of this heat treatment.

Grain growth in this foil was not significant; all grains remained below $1 \mu \mathrm{m}$ with most grains being several hundred nanometers in size. The high temperature heat treatment did not reset the microstructure sufficiently to prevent the nucleation and growth of the $\delta$ phase, which appeared in fairly high volume fraction at the expense of the $\gamma^{\prime \prime}$ phase. The $\delta$ phase is even coarser than that observed after the standard 718 heat treatment (Figure 6(a)) and the space between the precipitates is quite large indicative of an over-aged microstructure. The large presence of the $\delta$ phase is confirmed from the XRD plot shown in Figure 8(b). The clear double peak about the $\mathrm{Ni}$ (200) peak is either an indication of $\gamma^{\prime \prime}$ or $\gamma^{\prime}$ or both phases. Some finer precipitates tens of nanometers in size can be seen in the bright field image indicating that some $\gamma^{\prime}$ is 
present. It is interesting to note that the $\delta$ phase in these foils did not have a distinct needle like morphology. Blocky or plate like $\delta$ phase precipitates were seen in Sundararaman's work [6] when aging Inconel 718 at $950^{\circ} \mathrm{C}$ for 10 hours. At this point, it is not clear whether the larger precipitates are all $\delta$ phase or if the $1020^{\circ} \mathrm{C}$ heat treatment coarsened the grains and slowed the kinetics sufficiently to allow for some $\gamma^{\prime \prime}$ precipitation. Nevertheless, the XRD curves and electron micrographs point to a significant presence of $\delta$ precipitates.
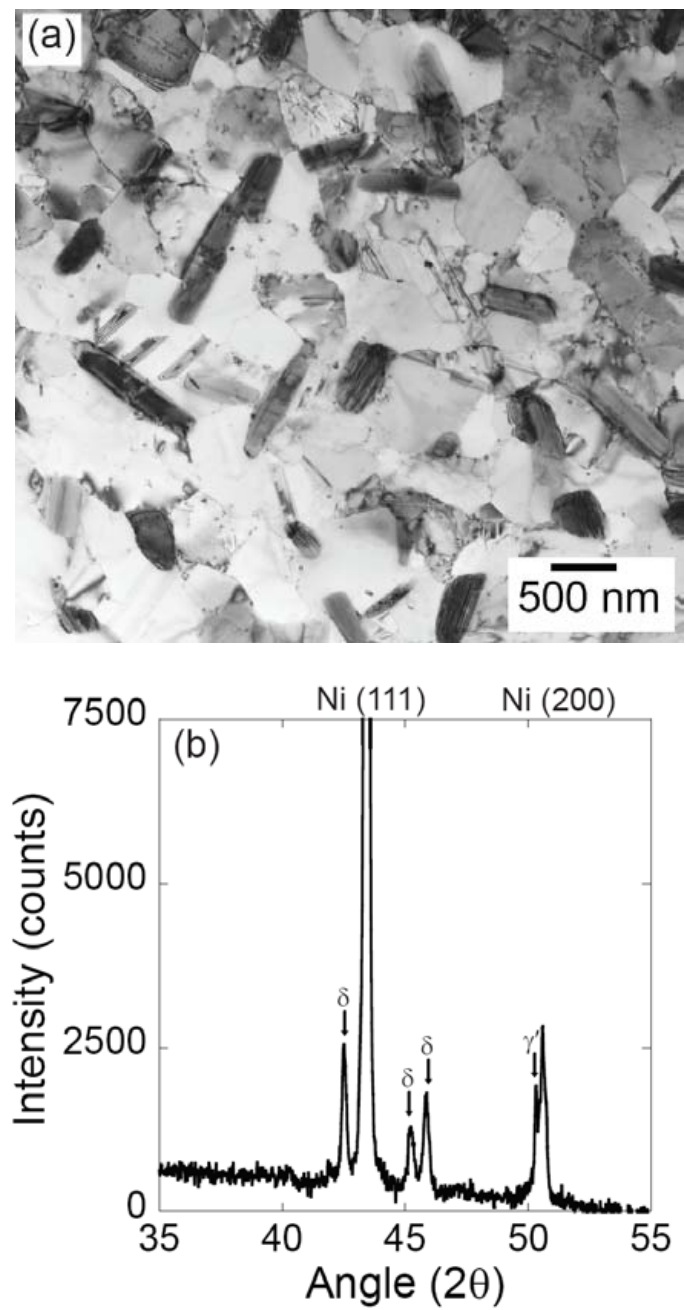

Figure 8. Foil subjected to a $1020^{\circ} \mathrm{C}$ heat treatment prior to a standard 718 heat treatment showing: (a) Bright field micrograph (b) XRD pattern of the alloy.

The mechanical properties of these foils were measured at $700^{\circ} \mathrm{C}$ as shown in Figure 9. The strength was found to be lower than the foils that had only received the standard heat treatment (Figure 7). The large size of the $\delta$ precipitates is likely responsible for the lower mechanical strength of the foil. Studies are underway to determine if even longer anneals at higher temperatures will enable sufficient grain growth to match the microstructure of the bulk alloys. Doing so is expected to allow for $\gamma^{\prime \prime}$ precipitation with attendant increases in mechanical properties.

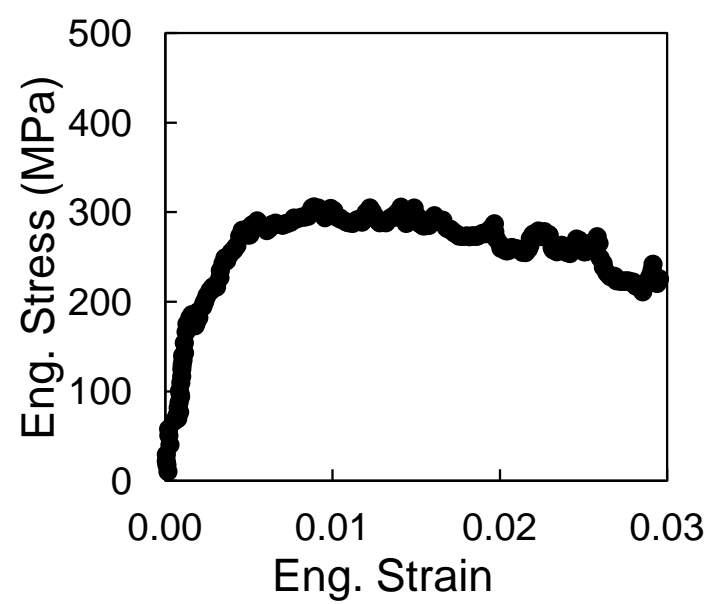

Figure 9. Stress-strain curve of a 718 foil tested at $700^{\circ} \mathrm{C}$ subject to a $1020^{\circ} \mathrm{C}, 30$ minute heat treatment prior to a standard 718 heat treatment.

\section{Conclusions}

Advanced Ni-based superalloys foils have been successfully sputtered with relatively low residual stresses. As-sputtered 718 foils were characterized to be fully nanocrystalline super-saturated solid solutions. Heat treatment of these nanocrystalline foils resulted in a dramatically different microstructure than the heat treatment of bulk 718 . The microstructural stability of the sputtered 718 foils was found to be excellent. Moreover, the precipitation kinetics of the sputtered foils were effected by the nanocrystalline grain size. Enhanced diffusion pathways and a decreased nucleation barrier at the grain boundaries appear to alter the precipitation pathways observed in bulk 718. Yield strengths of $400 \mathrm{MPa}$ at $700^{\circ} \mathrm{C}$ have been realized. While excellent by metallic thin film standards, this high temperature strength is not as high as for bulk 718 . The measured decrease in strength appears to be associated with the presence of $\delta$ phase precipitates. Taken together these results suggest that sputtered and properly heat treated superalloys have the potential to significantly extend the operating ranges of metallic MEMS and micro-devices.

\section{Acknowledgements}

The authors would like to thank the NSF for supporting this work under grant no. 0806753 and Haynes International, Inc. for providing the material. Additional thanks to Sara Barron and Mike Grapes of the Weihs research group who aided in the processing of the foils.

\section{References}

1. Zupan M., Hayden M.J., Boehlert C.J. \& Hemker K.J. 2001, "Development of high-temperature microsample testing", Experimental Mechanics, vol. 41, no. 3, pp. 242-247.

2. Haynes International, Inc. "Haynes 718 Alloy Brochure", 2001. Web. 18 January 2012. <http://www.haynesintl.com/> 
3. Slama C., Abdellaoui M. 2000, "Structural characterization of the aged Inconel 718", Journal of Alloys and Compounds, vol. 306, pp. 277-284.

4. Slama C., Servant C., Cizeron G. 1997, "Aging of the Inconel 718 alloy between 500 and $750^{\circ}$ C”, J. Mater. Res., vol. 12, no. 9, pp. 2298-2316

5. Sundararaman M., Mukhopadhyay P., Banerjee S. "Precipitation and Room Temperature Deformation Behaviour of Inconel 718”, Superalloys 718, 625, 706 and Various Derivatives, ed. E.A. Loria (Pittsburgh, PA: The Minerals, Metals \& Materials Society, 1994) 419-440.

6. Sundararaman M., Mukhopadhyay P., Banerjee S. 1988, "Precipitation of the $\delta-\mathrm{Ni}_{3} \mathrm{Nb}$ Phase in Two Nickel Base Superalloys”, Metallurgical Transactions A, vol. 19A, pp. 453465.

7. Burke M.G., Miller M.K. "Precipitation in Alloy 718: A Combined AEM and APFIM Investigation”, Superalloys 718, 625 and Various Derivatives, ed. E.A. Loria (Pittsburgh, PA: The Minerals, Metals \& Materials Society, 1991) 337-350.

8. Faheem M., McCormick S., Charit I. 2009, "Microstructural and DSC studies of Alloy 718 Plus", Thermochimica Acta, vol. 496, pp. 151-155.

9. Cao W., Kennedy R. "Application of Direct Aging to Allvac 718Plus Alloy for Improved Performance”, Superalloys 718, 625, and Derivatives 2005, ed. E.A. Loria (Pittsburgh, PA: The Minerals, Metals \& Materials Society, 1991) 213-222. 